\title{
LA ALEGORÍA DEL SUEÑO EN LOS AUTOS SACRAMENTALES DE CALDERÓN ${ }^{1}$
}

\author{
Enrique Duarte \\ Departamento de Literatura Hispánica \\ Facultad de Filosofia y Letras \\ Edificio de Bibliotecas \\ GRISO-Universidad de Navarra \\ 31080 Pamplona. Navarra. España \\ eduarte@unav.es
}

[Anuario calderoniano (ISSN: 1888-8046), 4, 2011, pp. 145-168]

\section{INTRODUCCIÓN}

Desde la Antigüedad, el hombre se ha visto irresistiblemente atraído por los sueños y los posibles significados e interpretaciones que tenían estos ${ }^{2}$. Gómez Trueba apunta algunos hechos significativos ya

${ }^{1}$ Este trabajo se enmarca en el proyecto de autos sacramentales financiado por la Subdirección General de Proyectos de Investigación (FFI2008-02319/FILO) cofinanciado por el FEDER. Cuenta también con el patrocinio de TC-12, en el marco del Programa Consolider-Ingenio (CSD2009-00033), del Plan Nacional de Investigación Científica, Desarrollo e Innovación Tecnológica.

${ }^{2}$ Utilizo para esta introducción el libro de Gómez Trueba, 1999, pp. 172-186; y Kagan, 1991, pp. 56 y ss. 
en la Antigüedad clásica: en la Ilíada de Homero se dice que los sueños proceden de Zeus y al principio del canto II, el propio Zeus envía un emisario a Agamenón para anunciarle las cosas que están por suceder. En la Odisea, Homero distingue dos puertas de donde salen los sueños: una de cuerno y otra de marfil. Los sueños verdaderos salen de la puerta de cuerno, mientras que la puerta de marfil produce los fal$\operatorname{sos}^{3}$. Este pasaje se reiterará en otros muchos textos a lo largo de la historia de la literatura ${ }^{4}$.

Platón estableció una relación entre los deseos reprimidos y los sueños, mientras que Aristóteles dejó una teoría bastante más coherente sobre ellos. Para este filósofo, Dios no interviene directamente para comunicarse con los hombres, aunque el problema sin resolver está en explicar los motivos por los que se pueden entrever acontecimientos futuros en ciertos sueños. Aunque algunos individuos pueden predecir el futuro en lo que sueñan, en la mayoría de los casos los sueños carecen de valor.

Una de las clasificaciones más citadas en la bibliografía resulta ser la de Macrobio en su Comentario del sueño de Escipión. Distinguía este autor cinco tipos en función de su valor profético: insomnium, visum o phantasma, somnium, visio y oraculum. Dos de ellos no tenían relación con acontecimientos futuros: el insomnium (pesadilla), y el visum (fantasma), que Macrobio consideraba una simple aparición. Los sueños proféticos los establecía de tres tipos: somnium o sueño alegórico; visio, literal y menos enigmático; y el oraculum, un sueño en el que por medio de un padre, una santa, una grave persona o un sacerdote (es decir, un medio) se advertía al soñador de algo relacionado con su futuro. Más tarde se añadirá una sexta categoría que son los sueños diabólicos.

${ }^{3}$ Ver Homero, Odisea, XIX, vv. 560 y ss.: «Porque dos son las puertas de los débiles sueños: una construida con cuerno, la otra con marfil. De estos, unos llegan a través del bruñido marfil, los que engañan portando palabras irrealizables; otros llegan a través de la puerta de pulimentados cuernos, los que anuncian cosas verdaderas cuando llega a verlos uno de los mortales».

${ }^{4}$ Ver Virgilio, Eneida, VI, vv. 1294-1299: «Dos puertas dicen / tiene el país del Sueño, una de cuerno, / que abre paso a las sombras verdaderas; / con brillo de marfil la otra relumbra, / pero por ella envían sueños falsos / los Manes a la tierra». Ver también Herrera, Anotaciones a la poesía de Garcilaso, pp. 813-814. 
En cuanto a la teología cristiana, se puede decir que se mantuvo la creencia en el sueño profético. Sin embargo, los Padres de la Iglesia se muestran cautos a la hora de admitir la influencia divina en los sueños. San Agustín veía dificultoso distinguir entre unos divinos y aquellos otros que eran producidos por causas naturales.

Santo Tomás de Aquino, en la Suma teológica ${ }^{5}$, establece que los hombres son instruidos por Dios mientras duermen como se puede leer en Job, 33, 15-16: «En sueños, en visiones nocturnas, cuando un letargo a los hombres invade, reclinados en su lecho, entonces abre él el oído del hombre y con apariciones le estremece». Incluso admite Santo Tomás que hubo santos varones que interpretaron sueños como ocurre con José, quien interpreta los del Faraón de Egipto, y Daniel, que clarificó el del rey de Babilonia. Establece dos causas para los sueños: una interna y otra externa. En cuanto a las causas internas, encontramos unas de orden psíquico, que explican que mientras el hombre duerme, vienen a su imaginación las preocupaciones y pensamientos que le ocuparon cuando estuvo despierto. Otras causas internas son de orden corporal, porque por la disposición interior de nuestro cuerpo surgen en la fantasía movimientos conformes con ella: así el hombre que abunda en humores fríos, sueña que está en agua y nieve y de esta forma los médicos analizan los sueños para poder establecer desórdenes humorales.

Las causas exteriores, a su vez, pueden ser de dos clases: corporales y espirituales. Son corporales aquellas en las que la imaginación del durmiente se siente afectada por el aire o por los cuerpos celestes. La fuente espiritual es el propio Dios quien puede, por medio de los ángeles, revelar a los hombres algunas verdades, como expresa el libro de los Números, 12, 6: «Si entre vosotros hubiera un profeta de Yavé, yo me revelaría a él en visión y en sueños le hablaría». Sin embargo, Santo Tomás también admite que los demonios pueden crear ciertas representaciones fantásticas anunciando acontecimientos futuros a aquellas personas que establecen pactos ilícitos con ellos.

Durante la época del Renacimiento y del Barroco, las clasificaciones de los sueños y sus causas se remontan a la época clásica. A pesar de las divisiones que causaban las guerras de religión, existía una cultura internacional de los sueños que compartían católicos y protes-

${ }^{5}$ Ver Santo Tomás, Suma Teológica, II-II, c. 95, art. 6. 
tantes ${ }^{6}$. Fernando de Herrera, por ejemplo, en las Anotaciones a la poesía de Garcilaso, al comienzo de la Égloga II, recoge estas mismas causas que establecía Santo Tomás: habría cuatro causas para explicar los sueños: dos internas y dos externas: los pensamientos y preocupaciones del hombre durante el día y los humores del cuerpo. En cuanto a las causas externas, la influencia del aire y los astros y el influjo de Dios a través de los ángeles.

Sin embargo, para la mayoría de los escritores españoles del Siglo de Oro, tres son las causas y la división de los sueños: natural, animal y celeste. Es decir, «se admitía la existencia de sueños originados por los humores corporales, por las preocupaciones diarias y por la intervención divina»?

Calderón, en sus autos sacramentales, recoge todas estas apreciaciones que informan su producción poética. En sus obras sacramentales encontramos un gran número de durmientes y soñadores que nos permite entender el sueño como un mecanismo complejo y muy dúctil que le concede una gran expresividad y le posibilita comunicar las verdades ocultas en el plano teológico de la alegoría. Una primera distinción en los autos sacramentales de Calderón sería la que se puede establecer siguiendo las dos acepciones de sueño en el Diccionario de Autoridades que distingue entre la acción de soñar, es decir, ver imágenes, historias que perturban el descanso humano y le impelen a la acción o a la interpretación de esas visiones («suceso o especies que en sueños se representan en la imaginación»), y la acción de dormir o descansar sin visiones anejas («acto de dormir») pero con una alta significación alegórica en los autos sacramentales ${ }^{8}$.

${ }^{6}$ Ver Kagan, 1991, pp. 56 y ss.

${ }^{7}$ Ver Gómez Trueba, 1999, p. 184.

${ }^{8}$ Ver Alatorre, 2003, p. 14: «Soñar y dormir son cosas distintas, pero íntimamente trabadas entre sí, sobre todo en nuestra lengua. ¡La expresión ;Oh dulce sueño! puede significar 'Que gran cosa el poder descansar sin interrupción durane siete horas, sobre todo para quien sufre o está fatigado!', pero también '¡Que sueño maravilloso tuve anoche!' Esa incómoda homonimia entre sueño 'el dormir' y sueño 'el soñar' no existe en latín (somnus y somnium) ni en las lenguas hermanas de la nuestra (italiano sonno y sogno, portugués sono y sonho, francés sommeil y rêve). Tampoco en griego (hynos, óneiros), ni en inglés (sleep, dream), ni en alemán (Schlaf, Traum)». 


\section{SoÑAdORES EN los aUtos SACRAMENTALES DE CALDERón}

Son muchísimas las obras sacramentales en las que Calderón hace uso de este recurso, tanto en aquellas en las que el sueño procede de Dios y sus mediadores, los ángeles, como los sueños falsos procedentes del demonio o de las fuerzas del mal. En algunos casos, Calderón utiliza como argumento pasajes de la Biblia en la que se nos narra las interpretaciones de José y Daniel a los sueños del Faraón y Nabucodonosor: son los autos sacramentales Mística y real Babilonia y Sueños hay que verdad son muy bien comentados por Françoise Gilbert en una serie de artículos 9 . Pero hay otros muchos títulos muy interesantes que no voy a poder comentar en profundidad: La cena del rey Baltasar ${ }^{10}$, El santo rey don Fernando, I y II parte ${ }^{11}$, La protestación de la fe, La devoción de la misa, El tesoro escondido, La piel de Gedeón, La lepra de Constantino ${ }^{12}$, No hay instante sin milagro, El cordero de Isaías y Primero y segundo Isaac son algunos ejemplos de este primer grupo de soñadores o visionarios que hemos establecido.

Mística y real Babilonia es un auto sacramental muy interesante de 1662 en el que se desarrolla la historia expuesta en el libro del profeta Daniel: partimos de una base bíblica que informa el argumento ${ }^{13}$. Gilbert ha estructurado el auto en tres fases: a) el problema la interpretación del sueño de Nabucodonosor y éxito por parte de Daniel; b) creación de una estatua del rey babilónico, negativa a la adoración y castigo del horno a los compañeros del profeta Daniel; c) la condena de la cava de los leones para Daniel y el pan eucarístico ${ }^{14}$.

En la primera fase, el rey se duerme con el llanto y el cántico apesadumbrado del pueblo hebreo, y su sueño constituye el campo de enfrentamiento entre las fuerzas antagónicas: por un lado la Idolatría,

${ }^{9}$ Gilbert, 2002 y 2005 a.

${ }^{10}$ La cena del rey Baltasar es estudiado por Gilbert, 2002.

11 Estudiados por Gilbert, 2005b.

12 En la que el emperador romano ve en un sueño a san Pedro y San Pablo y en una visión posterior en la que está despierto un ángel le muestra la señal de la cruz con la que vencerá en el campo de batalla a sus enemigos; una visión parecida de Constantino aparecerá también en No hay instante sin milagro, en la que ve al papa Silvestre vestido con las ropas pontificales.

13 Distingo entre asunto y argumento tal como lo hace Alexander A. Parker, 1983, pp. 46 y ss.

14 Gilbert, 2002. 
quien no puede adivinar el sueño que atormenta al rey, y por otro Daniel, quien ayudado por el ángel Gabriel relatará y lo interpretará con corrección. En un principio, los personajes no son capaces de ver lo que el rey sueña, tal como establece el texto de Daniel, 2 y el espectador observa al rey agitándose en su pesadilla:

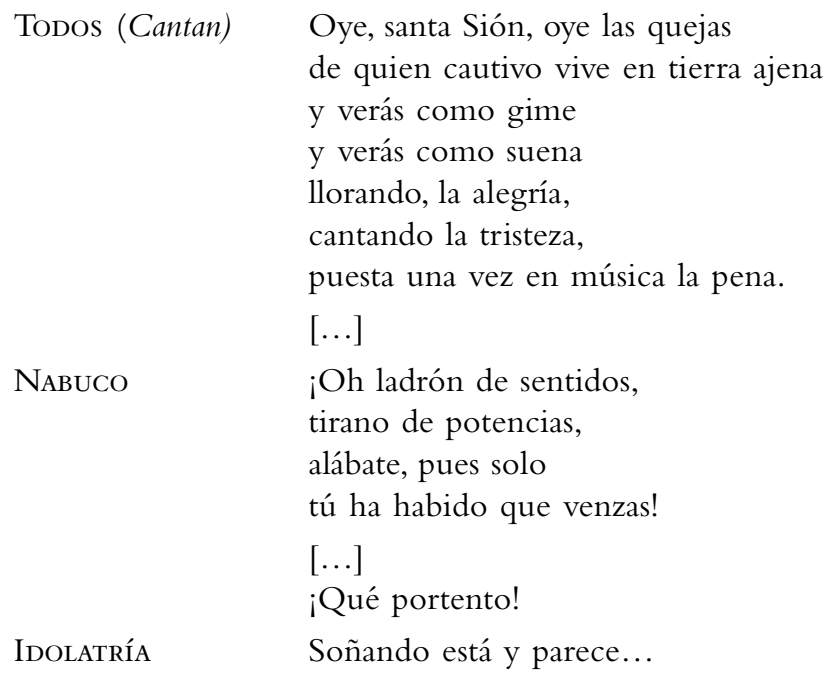

NABUCO

¡Qué prodigio!

IDOLATRÍA

Según que le estremece la pesadez...

NABUCO ¡Qué confusión!

IDOLATRÍA

NABUCO

IDOLATRÍA

NABUCO

IDOLATRÍA

NABUCO

IDOLATRÍA

A mis pies dio.

¿Qué angustia!

Un monte ve estivar.

¡Qué asombro!

¿Qué será su tormento?

No desvanezca tanta pompa el viento; ¡espera!

(Cae Nabuco a los pies de la Idolatría $)^{15}$

15 Calderón, Mística y real Babilonia, ed. Valbuena Prat, pp. 1052-1053. 
Idolatría no puede adivinar ni interpretar el sueño de Nabuco y será el ángel Gabriel quien inspire a Daniel el sueño y las claves para su interpretación. En la segunda parte del auto, la Idolatría intentará halagar a Nabuco con la construcción de una estatua que todos han de adorar como a Dios y ante la negativa de los jóvenes hebreos de adorarla, serán condenados al horno. El nuevo fracaso de la Idolatría marca el final de esta segunda etapa con el retiro de Nabuco del poder, proponiéndose vivir como un bruto en los montes ${ }^{16}$. La tercera parte del auto muestra la venganza que el hijo de Nabuco, llamado Donosor, y la Idolatría ejecutan en la persona de Daniel, al que culpan de todos sus fracasos, arrojándolo al foso de los leones. Sin embargo, el ángel Gabriel de nuevo intervendrá llevando a Abacuc con una cesta en la que se encuentra el cáliz y la hostia eucarísticas que salvarán a Daniel y al género humano. Estoy de acuerdo con Gilbert cuando explica que:

es lícito afirmar que el auto entero se construye alrededor del sueño de Nabuco como modalidad de la comunicación divina: el sueño es primero objeto y luego terreno de enfrentamiento, y sus elementos (la estatua) o sus equivalentes dramáticos (el ángel Gabriel) siguen, en las fases posteriores, estructurando la contienda entre la Idolatría y la revelación de la redención mesiánica, pregonada a lo largo del auto por el personaje de Daniel ${ }^{17}$.

Otro de los autos en los que el sueño es un elemento decisivo es el Tesoro escondido del año 1679. El auto comienza con el Gentilismo sentado en un bufete de su biblioteca leyendo por primera vez la Biblia. Asombrado ante las sombras y figuras de acontecimientos futuros que prometen las sagradas escrituras, se queda dormido y en sueños se le aparece la Inspiración, vestida de ángel. La principal duda que tiene Gentilismo es sobre el tesoro escondido que lee en las escrituras y la Inspiración le promete la guía, la estrella que guió a los reyes magos de oriente para encontrar la misteriosa tierra (Belén) donde se encuentra ese tesoro escondido:

16 Calderón, Mística y real Babilonia, ed. Valbuena Prat, pp. 1058-1063.

17 Gilbert, 2002, pp. 179-180. 
INSPIRACIÓN para que le descubras encenderé esta llama que hermosamente pura, fija y no errante estrella, en tus sentidos luzca ${ }^{18}$.

En el peor momento del Gentilismo en el que la Idolatría se opone a sus proyectos de hacerse con la tierra de Belén y Arabia, Tarsis y Sabá, que representan a los tres reyes de oriente, no están entusiasmados con su decisión, Inspiración encenderá la estrella que disipará sus dudas, los guiará al portal de Belén y ayudará a enfatizar la importancia del pan eucarístico por medio del oído, el sentido de la fe:

$\begin{array}{ll}\text { INSPIRACIÓN } & \text { Como aquesta maravilla } \\ & \text { se ha de mirar tan a ciegas } \\ & \text { que el oído ha de escucharla } \\ & \text { y cautivo ha de creerla } \\ & \text { de la Fe el entendimiento }{ }^{19} .\end{array}$

Otro auto llamativo es el titulado La protestación de la fe, que alegoriza los acontecimientos protagonizados por la famosa reina Cristina de Suecia. Este auto se prohibió su representación el 7 de junio de 1656 por orden del rey porque, según los Avisos de Pellicer, «las cosas de esta señora no estaban en aquel primer estado que tuvieron al principio, cuya casa y servicio de criados se compone ahora de sólo franceses $»^{20}$. En la época era un personaje muy famoso de la que sorprendía su masculinidad (se decía que montaba muy bien a caballo) y su carácter intelectual: las cartas que llegaban de la corte sueca la describían con la camisa manchada de tinta después de haber escrito mucho; se comentaba que conocía entre 10 y 11 idiomas, había leído casi todos los Padres de la Iglesia y tenía una prodigiosa memoria. Calderón la representa en este auto leyendo a San Agustín.

Este auto sacramental se basa en la alegoría del banquete de bodas que aparece en Mateo, 22, 8-14, donde se cuenta que son muchos los invitados que rechazan su asistencia a la fiesta y se ha de invitar a los

18 Calderón, El tesoro escondido, ed. Valbuena Prat, p. 1668.

19 Calderón, El tesoro escondido, ed. Valbuena Prat, p. 1688.

${ }^{20}$ Ver Calderón, La protestación de la fe, ed. Andrachuck, p. 15. 
pobres y mendigos. La Herejía oye la invitación que lanza la Sabiduría desde la Jerusalén celestial y decide estropear el banquete con la ayuda de Inglaterra y las naciones protestantes, sobre todo de Suecia y su reina, Cristina, a la que hará la reina de la herejía (vv. 400 y ss.). Sin embargo, la Sabiduría explota la etimología de Cristina para convertirla en cristiana y hacer de ella una de las asistentes al banquete eucarístico. De este modo se entabla entre la Sabiduría y la Herejía el duelo alegórico.

Sale al escenario Cristina de Suecia (vv. 527 y ss.) y despojándose de los elementos que representan su poder militar (el arnés, la espada y la bengala) se pone a estudiar manifestando su atracción por los libros y su desapego del poder. El libro que está leyendo de San Agustín le presenta pasajes que le traen muy confusa y se refiere a los problemas de la predestinación en relación al libre albedrío. La reina de Suecia confiesa que ha escrito al rey de España pidiéndole ayuda intelectual (vv. 591 y ss.) y así se queda dormida encima de sus libros y sueña con un etíope que está leyendo el libro de Isaías y que, como ella, no entiende la escritura hasta San Felipe se las explica convenciéndolo para que acepte el bautismo (vv. 674-676) ${ }^{21}$. Es entonces cuando un soldado la despierta y le anuncia que el rey Felipe IV le ha enviado un embajador. La Reina Cristina se sorprende de que cuando sueña con un Felipe el destino le reserve otro Felipe para ella.

El sueño anticipa la futura conversión de Cristina de Suecia gracias a la acción diplomática de España y su participación en el banquete eucarístico final, en el que Herejía intenta hacerse con formas consagradas para profanarlas. Pero como la diabólica Herejía no lleva las vestes nupciales que proporciona la penitencia, será el Brazo Eclesiástico el encargado de expulsarla de carro donde se representa la apoteosis eucarística para caer en manos del Brazo Seglar quien procede a su ejecución.

El último auto sacramental que puedo comentar es el titulado $\mathrm{La}$ devoción de misa, fechado en 1658. Representa este auto una leyenda europea muy conocida: la de caballero cristiano que por asistir a su devoción diaria de escuchar misa deja de asistir a un torneo o a una batalla y que en España la encontramos en textos como la Cantiga 63

21 Se representa el pasaje de Hechos, 8, 26-40. 
y La primera crónica general de Alfonso X, el sabio; los Castigos y documentos de Sancho IV o el Liber Mariae de Juan Gil de Zamora ${ }^{22}$.

El auto comienza con la lucha que mantienen el Ángel con la Secta de Mahoma, para ver quien tiene la primacía en el poder sobre España en vísperas de una batalla entre cristianos y musulmanes cerca de san Esteban de Gormaz (Soria). Deciden continuar su enfrentamiento apareciéndose a cada uno a los jefes de sus huestes para ver quien vence la batalla: el Ángel se le muestra al conde de Castilla, Garci Fernández y la Secta al temible Almazor.

\section{Cantando hacia un carro}

ÁNGEL

Conde ilustre de Castilla.

Representando hacia otro

SETA

Rey de Córdoba la bella.

ÁNGEL

Invicto Garci Fernández, godo Atlante de la Iglesia.

SETA

Grande Almanzor africano, Alcides de la ley nuestra.

Ábrense los dos carros que serán dos tiendas de campaña y vese en el uno el conde Garci Fernández, viejo venerable, armado de todas armas, sentado durmiendo $y$ en el otro Almanzor durmiendo también sentado en otra silla ${ }^{23}$

El sueño que se representa constituye un episodio más del enfrentamiento Ángel-Secta que comienza el auto sacramental. Sirve para presentar a los dos contendientes y asegurar la victoria, pues el Ángel tomará el lugar del caballero ausente de la batalla que se queda atendiendo las misas del día.

Como hemos visto en estos breves ejemplos anteriores, el sueño, en cuanto visiones o apariciones celestiales o demoniacas, no constituye simplemente un recurso escénico y estético más. Tanto en los autos cuyo argumento está basado en pasajes bíblicos que narran de forma literal sueños (Mística y real Babilonia y Sueños hay que verdad son) como otras obras cuyo argumento no tendrían por que presentar tal

22 Para más detalles, ver la «Introducción» de la edición de Calderón, La devoción de la misa, ed. Duarte.

${ }^{23}$ Ver Calderón, La devoción de la misa, ed. Duarte, vv. 366 acot.-372 acot. 
recurso, el dramaturgo se sirve de esta técnica escénica para estructurar la obra, anticipar el desarrollo futuro de esta y proporcionar el enfrentamiento y la tensión necesarios para el desarrollo argumental dramático.

\section{Durmientes en los autos sacramentales de Calderón}

Una simple lectura de las obras sacramentales de Calderón nos sirve para tropezarnos con una serie de personajes durmientes que comunican distintos significados alegóricos que permiten el perfecto acoplamiento de los planos de la alegoría, la construcción de esta imprescindible en el auto y que el público pueda entender y disfrutar la obra. Me refiero a muchos personajes que representan su papel dormidos en determinado momento sin comunicarnos sueño alguno, entendido este como visión imaginativa o pesadilla. Hay que señalar que nos encontramos con un recurso muy utilizado y que presenta distintas significaciones.

\section{El sueño como muerte}

Este es uno de los tópicos más repetidos y conocidos en los autos sacramentales y en literatura del Siglo de Oro. San Agustín escribe que el sueño de la muerte vendrá, quiérase o no (Sermón, 93, 8) y en el Sermón, 361, 10, compara al dormir con el morir y al despertar con el resucitar. Garcilaso en el soneto XVII, versos 9-11, escribe: «Del sueño, si hay alguno, aquella parte / sola que es ser imagen de la muerte / se aviene con el alma fatigada", pasaje al que el comentario de Herrera añade abundante documentación clásica del motivo en Homero, Hesíodo, Virgilio, Eliano, y otros muchos, entre ellos Ovidio. Quevedo, en los Sueños, explica que: «el sueño de cada día os acuerda de la muerte retratándola en sí» ${ }^{24}$; y en un poema dedicado al sueño indica:

24 Quevedo, Los sueños, ed. Arellano, pp. 208-209. 
No te busco yo por ser descanso sino por muda imagen de la muerte ${ }^{25}$.

Calderón gusta de un estilema que repite en muchísimos autos sacramentales en el que compara el sueño con la muerte a través de las plantas narcóticas (opio, beleño y cicuta) que se crían en los llamados montes de la luna, lugar donde legendariamente se pensaba que nacía el río Nilo. En Andrómeda y Perseo, por ejemplo, el Demonio se dirige a la Medusa de la siguiente manera:

DEMONIO

¡Oh tú, que el pavoroso obscuro seno
de esa bruta coluna
del venenoso monte de la luna
habitas, ponzoñosa y escondida,
mágico parasismo de la vida,
madre horrible del sueño,
alimentada furia del beleño,
susto de los mortales,
línea a los bienes, término a los males,
mesonera del llanto,
huéspeda de los reinos del espanto,
reloj de los momentos,
precisa acotación de los alientos,
separación penosa
de la más dulce unión ${ }^{26}$.

La estructura se repite con muchas variantes en diferentes autos sacramentales como La vida es sueño, El pintor de su deshonra, El jardín de Falerina, El tesoro escondido, La cena del rey Baltasar, El valle de la zarzuela y La cura y la enfermedad. En todos estos autos sacramentales se identifica al sueño con la muerte y las consecuencias de la ingestión de los tóxicos producidos por el beleño, el opio o la cicuta.

Sin embargo, esta identificación de la muerte y el sueño se dramatiza en algunos de los autos de manera mucho más explícita. Así, por ejemplo, en El pleito matrimonial del cuerpo y el alma, el dramaturgo re-

25 Quevedo, Poesía original, ed. Blecua, vv. 5-6. Ver, para muchos más ejemplos, la nota 63 a la edición del auto sacramental de Calderón, El indulto general, ed. Arellano y Escudero.

${ }^{26}$ Ver Calderón, Andrómeda y Perseo, ed. Ruano de la Haza, vv. 335-349. 
presenta el sueño del Cuerpo humano, mientras que el Alma intenta seguir razonando:

Cuerpo

Alma

Muerte

Alma

VIDA

Entendimiento Cielos, ¿qué es lo que me ha dado

MEMORIA

VOLUNTAD

Muerte

Alma

Pecado que de repente he cegado?

Sí oiré, di mientras ahora

un poco me echo a dormir.

Prosigue, pues, que rendido

al sueño te oigo.

(Échase a dormir)

Sí haré,

que voz del alma bien sé

que te ha de coger dormido.

Ser eterno el cielo santo

me dio.

Aquí mi efecto empieza.

Mas, ¿qué pasmo, qué torpeza

me embarga la voz?

Con ser Memoria perdí

la memoria.

¡Oh variedad

de especies, ya eres mi dueño!

La última de quien al sueño

se entrega es la voluntad

Pues proseguir tengo, aunque...

Pero yo... ¿Cuándo? ¡Ay de mí!

(Con turbación)

[...]

Luego aunque dormir no puedo

yo, faltándome con quien

pueda explicarme, también

confusa y suspensa quedo.

(Quédase como elevada)

Este común frenesí, letargo o delirio fuerte 
que a todos ha dado muerte, ¿no es efecto tuyo?

Muerte

Sí.

PeCADO

Bien se deja conocer si en sus acciones advierto el cuerpo un cadáver yerto que, siendo, deja de ser; el alma en suspensa calma, porque viéndose embargar los órganos para obrar, solo el no dormirse el alma debe a su inmortalidad ${ }^{27}$.

Pero hay otros muchos ejemplos. En La piel de Gedeón, este juez hebreo comenta al ver los dos campos dormidos:

¡que poco dista un difunto de un dormido fatigado! ${ }^{28}$

En El tesoro escondido, se describe de nuevo al sueño comparándolo con la muerte:

aquel familiar ladrón que en las vigilias nocturnas, hipócrita del descanso, la media vida nos hurta; pues el rato que posee las pasiones, pone en duda, si es que está la muerte viva o está la muerte difunta ${ }^{29}$.

En La siembra del señor, el propio personaje del sueño se define en sus primeras intervenciones como muerte ${ }^{30}$; en Los encantos de la cul-

${ }^{27}$ Ver Calderón, El pleito matrimonial del cuerpo y el alma, ed.Valbuena Prat, p. 87.

${ }^{28}$ Ver Calderón, La piel de Gedeón, ed. Armandáriz, vv. 1419-1420.

${ }^{29}$ Ver Calderón, El tesoro escondido, ed. Valbuena Prat, p. 1669.

${ }^{30}$ Ver Calderón, La siembra del señor, ed. Valbuena Prat, p. 683: «Soy aquel / que a cobrar va de la humana / vida el tributo primero / que ofrece a la muerte». 
pa, el hombre, tras haber enviado a sus sentidos a reconocer la isla de Circe se echa a dormir a la sombra de un ciprés, árbol dedicado a la muerte por excelencia ${ }^{31}$.Y en La segunda esposa y triunfar muriendo encontramos un curioso juego escénico en el que la muerte va apagando al hombre las velas de su vida hasta que le deja solo una:

\author{
Mira cómo mi crueldad \\ mata desde el primer día \\ con el sueño, imagen mía, \\ de esa antorcha una mitad. \\ Quita una vela del hacha y apágala \\ Mira a hambre y sed cómo luego \\ otra mitad desfallece.
}

Otra

Mira el mal que se padece cuánto apaga de ese fuego.

Otra

Mira ansia, angustia, tristeza, cansancio, ambición y anhelo,

Otra

desdicha, pena y desvelo necesidad y pobreza,

Otra

de aquesa luz que recibes, cómo apagan cuanto toco y mira agora cuán poco aun de lo que vives, vives.

Queda con una vela sola ¿Qué se hizo la llama bella que a despecho de los dos ardía?32

31 Ver Calderón, Los encantos de la culpa, ed. Escudero, vv. 238-247: «ENTENDIMIENTO: ¡Qué bien / para dormir los sentidos / apartas de ti! Pues es / cierto que queda sin ellos / el que duerme; y cuán bien fue / ciprés el árbol que aquí / tomaste para ti, pues / viene a ser árbol de muerte, / de quien el sueño también / es sombra».

32 Ver Calderón, La segunda esposa, ed. García Ruiz, vv. 805-823. 
Por lo tanto, en esta selección de ejemplos vemos como la identificación del sueño y la muerte es muy común en los autos sacramentales de Calderón. Esta identificación permite crear una serie de juegos escénicos que comunican las verdades teológicas dispuestas en el plano alegórico.

\section{El sueño como pecado}

Hay que tener en cuenta que para la Iglesia, el pecado era la muerte del alma, por lo que el sueño es fácilmente identificado con este. Para Ott, «el concilio de Trento denomina al pecado original muerte del alma. La muerte del alma es la carencia de la vida sobrenatural, es decir, de la gracia santificante» ${ }^{33}$.Y San Agustín, en La ciudad de Dios, explica que: «la muerte del alma tiene lugar cuando la abandona Dios, como la del cuerpo cuando el alma se aleja. Luego la muerte de los dos, es decir, del hombre entero, acaece cuando el alma, abandonada de Dios, abandona el cuerpo» ${ }^{34}$.

En El nuevo hospicio de pobres se representa la alegoría de las bodas de la Naturaleza humana con Cristo, el Hijo. El Rey, Dios Padre, dice que la humana naturaleza vive dormida como consecuencia del pecado original:

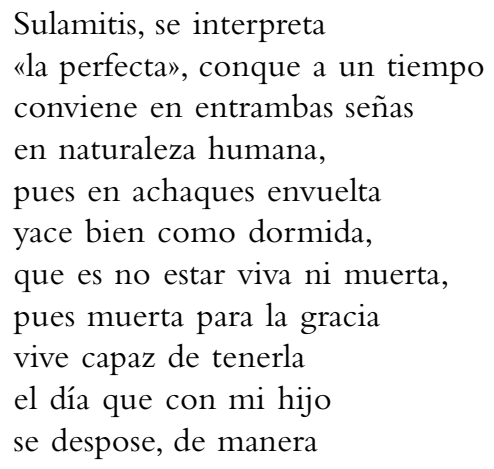

${ }^{33}$ Ver Ott, 1960, p. 187.

${ }^{34}$ Ver San Agustín, La ciudad de Dios, libro XIII, cap. II. Para mas datos ver Arellano, 2000, s. $v$. pecado, muerte del alma. 
que de sus joyas dotada vendrá a quedar tan perfecta ${ }^{35}$.

En el auto sacramental titulado La vida es sueño, se representa al Hombre comiendo la manzana del jardín del Edén y como consecuencia del veneno del pecado original queda traspuesto y dormido, por lo que los cuatro elementos le han de llevar de nuevo a la cueva prisión donde queda aletargado:

Poder

vosotros, ya sin ninguna

obediencia, retiradle

a él también, que a la profunda

tierra de donde salió

es bien que se restituya.

Dejádsele allí a esa fiera

poderosa sombra injusta,

que contra su Entendimiento

cautelosamente triunfa.

Sufra, llore, gima y sienta

cuanto un pecado le muda,

al ver, de un instante a otro,

que el que su primera cuna

durmió en brazos de la Gracia

despierta en los de la culpa ${ }^{36}$.

A partir de este momento, el Hombre representa su papel dormido. En La nave del mercader el Hombre, al beber de la copa del pecado que le ofrece el demonio, cae desmayado al suelo:

Hombre ¿qué mortal veneno infunde

en mí esta bebida que

al labio apenas la puse

cuando corrió al corazón

que solo para eso tuve?

LAscivia ¿Qué veneno ha de ser? Es el que en su aliento produce la hidra por siete bocas

${ }^{35}$ Ver Calderón, El nuevo hospicio de pobres, ed. Arellano, vv. 106-118.

${ }^{36}$ Ver Calderón, La vida es sueño, ed. Valbuena Prat, p. 1400. 
que humo exhalan, fuego escupen.

Demonio Su sangre has bebido; que esa dorada copa que truje aquella es con que brindando ramera mujer discurre el mundo.

[...]

HOMBRE

¡Ay infelice de mí! que aunque quejarme procure de que el amigo me ultraje y la sirena me injurie no puedo, porque el furor, la ira, la rabia, confunden tanto mis sentidos, tanto mis potencias destituyen que con la luz del sol todo me falta, todo me huye, sino sola la razón porque a par del dolor dure.

Cae en brazos del Demonio. [...] Déjale caer desmayado ${ }^{37}$

En Los encantos de la culpa, el Hombre-Ulises rescata a sus sentidos embrutecidos por la acción de Circe-culpa y estos hablan del pecado como de un letargo ${ }^{38}$. Por último, en El Indulto general se explica que todos los hombres nacen con el pecado original y todos los hombres se encuentran en la cárcel del mundo durmiendo:

\title{
Culpa
}

\begin{abstract}
¡Ah del pavoroso centro, en que delincuentes yacen, no sólo cuantos nacieron, porque nacieron, sino cuantos por ser herederos de aquel original crimen, infestados se adurmieron a la sombra de la muerte,
\end{abstract}

${ }^{37}$ Ver Calderón, La nave del mercader, ed. Arellano, vv. 1615-1645.

${ }^{38}$ Ver Calderón, Los encantos de la culpa, ed. Escudero, vv. 692-693: «De qué letargo tan dulce / a esta nueva voz despierto!». 
en el más profundo sueño de la vida! ${ }^{39}$.

El sueño como caracterizador de personajes

En algunos autos sacramentales los personajes aparecen durmiendo y el sueño los caracteriza. En El cordero de Isaías, el Descuido se duerme e invita al Hombre a hacerlo también ${ }^{40}$.

En Pisquis y Cupio para Madrid, la Tercera Edad, que es quien se va a casar con Cupido, tiene dos sirvientes: la Sencillez y la Malicia; como la Tercera Edad, es decir, Psiquis, quiere saber una noche cómo es Cupido, la Sencillez se queda dormida, mientras que la Malicia la acompaña a descubrir el velo (eucarístico) que trae Cupido ${ }^{41}$.

En el auto sacramental $A$ Dios por razón de estado, se nos muestra a otro personaje, Ateísmo, durmiendo. Ingenio y Pensamiento han escuchado el terremoto que se produce después de la muerte de Cristo y quieren saber cuál ha sido la causa buscando un Dios pasible por el que se lamenta toda la creación. Recorriendo el orbe llegan a América donde los recibe un dormido Ateísmo al que no le importa en absoluto la búsqueda del Dios pasible:

Ábrese un peñasco y vese en él el Ateísmo durmiendo en el traje que dicen los versos

La filosofia del Ateísmo es clara y está en consonancia con su actitud vital:

Атвísmo

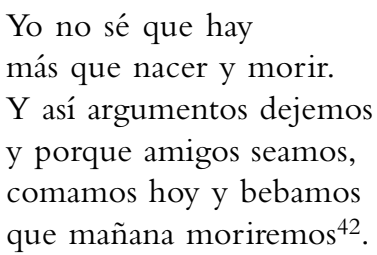

\footnotetext{
${ }^{39}$ Ver Calderón, El indulto general, ed. Arellano y Escudero, vv. 55-64.

40 Calderón, El cordero de Isaías, ed. Pinillos, vv. 935 y ss.

41 Calderón, Psiquis y Cupido para Madrid, ed. Valbuena Prat, pp. 384-385.

42 Calderón, A Dios por razón de estado, ed. Duarte, vv. 825-830.
} 
Es interesante la caracterización que se hace también de Noé en La torre de Babilonia, al que se le describe durmiendo tras haber consumido el mosto fermentado que acaba de descubrir, como nos lo cuenta el pasaje de Génesis, 9, 20-25. Calderón sigue literalmente este pasaje de la Biblia y aprovecha para alegorizar este vino descubierto por Noé que se convierte en la bebida eucarística:

Nó́

$$
\begin{aligned}
& \text { ¡Válgame el cielo! } \\
& \text { ¡Qué de cosas mi desvelo } \\
& \text { aquí me ha representado! } \\
& \text { ¡Qué de misterios soñado, } \\
& \text { que yo por la fe las creo, } \\
& \text { pues me parece que veo } \\
& \text { vino y pan sacramentado! } \\
& \text { Del cielo inspirado yo } \\
& \text { aquel racimo exprimí } \\
& \text { y el rubio licor bebí, } \\
& \text { cuya fuerza me dejó } \\
& \text { sin mí, pues me enajenó } \\
& \text { en mí mismo suspendido: } \\
& \text { alto misterio escondido } \\
& \text { tiene cuyo sacramento } \\
& \text { cautivó mi entendimiento } \\
& \text { y me privó de sentido; } \\
& \text { porque este vino será } \\
& \text { materia de un peregrino } \\
& \text { sacramento, que de vino } \\
& \text { en sangre convertirá } \\
& \text { inmenso poder que hará } \\
& \text { milagro tan señalado }{ }^{43} \text {. }
\end{aligned}
$$

El sueño como caracterizador de ideas teológicas

Es muy interesante observar cómo Calderón se sirve de este recurso para comunicar ideas teológicas que se encuentran en el plano alegórico y que permiten que el público interprete correctamente la

43 Calderón, La torre de Babilonia, ed. Valbuena, p. 875. 
alegoría. Nos encontramos varios casos que voy a comentar con mucha brevedad.

Es muy común en los autos sacramentales presentarnos a Cristo durmiendo en espera de su venida. En esa acción se muestra la idea del cumplimiento de la promesa del Mesías y las esperanzas que ha tener el hombre del Antiguo testamento hasta que finalmente se cumple el tiempo y la promesa. Este recurso escénico está en relación también con muchos pasajes de la Biblia ${ }^{44}$. En El diablo mudo, por ejemplo, se nos presenta de manera muy gráfica:

Ábrese el otro carro, que será un globo terrestre, y vese en él sentado en otro trono de flores el Amor de Peregrino, la mano en la mejilla, como dormido; y, en elevación también de canales, baja a su tiempo por otra escala, cuyos Ángeles estarán en acción de subir ${ }^{45}$.

Este recurso de Cristo durmiendo esperando el tiempo en el que se cumple la profecía de su encarnación es bastante común y aparece en otros autos sacramentales como La nave del mercader ${ }^{46}$, La humildad coronada de las plantas ${ }^{47}$ y La divina Filotea ${ }^{48}$.

Muy parecido es el recurso de mostrar al Hombre dormido antes de su creación, normalmente en un cueva o vestido de pieles, indicando la precariedad de la no existencia, «el estado de desnudez y desamparo en que se encuentra el hombre al nacer: en la comedia primariamente frente al destino natural y en los autos frente al destino sobrenatural, y sugieren a veces un estado espiritual primitivo y en ocasiones turbulento o negativo; pueden simbolizar los groseros afec-

44 Por ejemplo el Salmo 43, que utiliza Calderón en los Misterios de la misa, ed. Duarte, vv. 450-463 y, sobre todo, en relación de las semanas de Daniel. Ver el Diccionario de los autos sacramentales de Calderón.

45 Calderón, El diablo mudo, ed. García Valdés, v. 598 acot.

${ }^{46}$ Ver Calderón, La nave del mercader, ed. Arellano, v. 203 acot.: «Ábrese la nube y vese en ella el Mercader, vestido de armenio, dormido, y el Amor, despierto».

47 Calderón, La humildad coronada de las plantas, ed. Arellano, vv. 788-798: «pero / estar, aunque a esto he venido, / hasta que sea tiempo, quiero / ignorado y escondido; / y así, a mi sombra podré / descansar la siesta, dando / tiempo al tiempo, para que / las hebdómadas pasando, / llegue el triunfo de la fe. / Al blando sueño rendido / estoy».

48 Calderón, La divina Filotea, ed. Galván, vv. 558-559: «No atribuyas a olvido / el fingirme dormido». 
tos humanos» ${ }^{49}$. Un ejemplo se puede ver el auto sacramental Tu prójimo como a ti:

Ábrese un peñasco y en él el Hombre dormido, vestido de pieles, y el deseo hablándole al oído, de pieles también ${ }^{50}$.

Semejante recurso lo encontramos en La vida es sueño ${ }^{51}$ o La nave del mercader ${ }^{52}$.

También se desarrollan pequeñas acciones para comunicar conceptos teológicos. En el auto sacramental Tu prójimo como a ti, se nos presenta la Culpa que ha estado velando toda la noche quedándose dormida al amanecer, momento en el que aparece la Virgen, Alba, quien ayudada por la gracia pasa sin ser contaminada por la Culpa ${ }^{53}$. Así de ingeniosa se representa la Inmaculada Concepción de María.

\section{CONCLUSIONes}

Como hemos visto a lo largo de estas páginas, el recurso escénico del sueño es muy utilizado y versátil para poder apoyar todos los recursos que despliega la alegoría. He creído ver dos diferencias muy marcadas entre el sueño como visión y el simple acto del dormir, aunque, como en todas las clasificaciones, hay ejemplos que podrían compartir distintas categorías. Lo cierto es que no se puede pensar en el sueño como un simple recurso ornamental o estético, sino que, por el contrario, en el caso de las visiones celestiales o demoníacas el sueño constituye el terreno del enfrentamiento de las fuerzas antagónicas participantes en la obra sacramental, estructuran el desarrollo de la obra y anticipan la resolución del conflicto. Son estas razones y los numerosos ejemplos encontrados los que permiten concluir que Calderón utilizó el recurso del sueño como un elemento importante más en el complejo mundo del auto sacramental.

${ }^{49}$ Ver Arellano, Diccionario de los autos sacramentales de Calderón, 2000.

50 Calderón, Tu prójimo como a ti, ed. Valbuena, p. 1412.

51 Calderón, La vida es sueño, ed. Valbuena, p. 1394: «Descúbrese un peñasco, y el Hombre vestido de pieles y la Gracia con un hacha».

${ }^{52}$ Ver Calderón, La nave del mercader, v. 154 acot.: «Ábrese el peñasco y vese en él el Hombre vestido de pieles, dormido, y el Deseo, despierto».

53 Calderón, Tu prójimo como a ti, ed.Valbuena, pp. 1431-1434. 


\section{Bibliografía}

Alatorre, A., El sueño erótico en la poesía española de los Siglos de Oro, México, Fondo de Cultura Económica, 2003.

Arellano, I., Diccionario de los autos sacramentales de Calderón, Kassel, Reichenberger, 2000.

Calderón de la Barca, P., A Dios por razón de estado, ed. J. E. Duarte, Kassel, Reichenberger, (en prensa).

- El cordero de Isaías, ed. M. C. Pinillos, Kassel, Reichenberger, 1996.

- El diablo mudo, ed. C. C. García Valdés, Kassel, Reichenberger, 1999.

- El indulto general, ed. I. Arellano y J. M. Escudero, Kassel, Reichenberger, 1996.

- El tesoro escondido, en Obras completas. Autos sacramentales, ed. Á. Valbuena Prat, Madrid, Aguilar, 1987, vol. 3, pp. 1661-1688.

- La devoción de la misa, ed. J. E. Duarte, Kassel, Reichenberger, 2001.

- La humildad coronada, ed. I. Arellano, Kassel, Reichenberger, 2002.

- La nave del mercader, ed. I. Arellano, Kassel, Reichenberger, 1996.

- La piel de Gedeón, ed. A. Armendáriz, Kassel, Reichenberger, 1998.

- La protestación de la fe, ed. G. P. Andrachuk, Kassel, Reichenberger, 2001.

- La segunda esposa y triunfar muriendo, ed. V. García Ruiz, Kassel, Reichenberger, 1992.

- La siembra del Señor, en Obras completas. Autos sacramentales, ed. Á. Valbuena Prat, Madrid, Aguilar, 1987, vol. 3, pp. 682-698.

- La torre de Babilonia, ed. Á. Valbuena Prat, Madrid, Aguilar, 1987, vol. 3, pp. 871-888.

- Los encantos de la culpa, ed. A. Egido, y J. M. Escudero, Kassel, Reichenberger, 2004.

- Mística y real Babilonia, en Obras completas. Autos sacramentales, ed. Á.Valbuena Prat, Madrid, Aguilar, 1987, vol. 3, pp. 1041-1066.

- Psiquis y Cupido para la villa de Madrid, en Obras completas. Autos sacramentales, ed. Á. Valbuena Prat, Madrid, Aguilar, 1987, vol. 3, pp. 367-386.

Gilbert, F., «Función dramática y representación del sueño en dos autos de Calderón: La cena del rey Baltasar (1634) y Mística y Real Babilionia (1662)», Criticón, 86, 2002, pp. 159-196.

- «Función y alcance del sueño en el auto de Calderón La cena del rey Baltasarn, en Actas del XIV congreso de la Asociación Internacional de Hispanistas. New York, 16-21 de julio de 2001. II: Literatura española, siglos XVI $y$ XVII, ed. I. Lerner et al., Newark, Delaware, Juan de la Cuesta, 2004, vol. 2, pp. 255-260.

- «Funciones del sueño en un auto de Calderón: Sueños hay que verdad son», Bulletin of the Comediantes, 57, 2, 2005a, pp. 441-489. 
- «Sueño y santidad en el auto de Calderón El santo rey don Fernando, primera y segunda parte», en Homenaje a Henri Guerreiro. La hagiografía entre historia y literatura en la España de la Edad Media y del Siglo de Oro, ed. M. Vitse, Madrid / Frankfurt, Iberoamericana / Vervuert, 2005b, pp. 669-682.

Gómez Trueba, T., El sueño literario en España: consolidación y desarrollo del género, Madrid, Catedra, 1999.

Herrera, F. de, Anotaciones a la poesía de Garcilaso, ed. I. Pepe y J. M. Reyes, Madrid, Cátedra, 2001.

Homero, Odisea, ed. J. L. Cano, Madrid, Cátedra, 1990.

KagAn, R. L., Los sueños de Lucrecia: política y profecía en la España del siglo XVI, Madrid, Nerea, 1991.

Parker, A. A., Los autos sacramentales de Calderón de la Barca, Barcelona, Ariel, 1983.

Quevedo, F. de, Los sueños, ed. I. Arellano, Madrid, Cátedra, 1991.

- Poesía original completa, ed. J. M. Blecua, Barcelona, Planeta, 1981.

Virgilio, Eneida, ed. J. C. Fernández Corte; tr. A. Espinosa Pólit, Madrid, Cátedra, 2003. 